\title{
Fundamental Mechanisms of Pore Formation in Iron Ore Sinter and Pellets
}

\author{
Y-H. YANG') and N. STANDISH ${ }^{2)}$
}

1) Department of Mathematics, The University of Wollongong, Wollongong, NSW 2500, Australia. Engineering, The University of Wollongong, Wollongong, NSW 2500, Australia.

2) Department of Materials

(Received on October 1, 1990; accepted in the final form on December 14, 1990)

\begin{abstract}
The fundamental pore formation mechanism in iron ore sinter and pellets was investigated, using iron ore/limestone tablets with and without addition of coke. The results showed that pores were formed at the sites of limestone and coke particles, and that the particle size and amount of limestone and coke particle size all had strong effect on the pore structure. Different types of pores in sinter and pellets were classified in terms of their origins. These results are useful in understanding the sintering and pelletizing process.
\end{abstract}

KEY WORDS: pore formation; sintering process; pelletizing process; ironmaking; limestone.

\section{Introduction}

The majority of modern blast furnaces use iron ore sinter and pellets as the iron feed to the burden.1) The tonnages of world production of both sinter and pellets and their proportions in blast furnace burdens have steadily increased over the years. ${ }^{2-4}$ It is estimated that overall, lump ores, sinter, and pellets are used in proportions of $1: 2: 1$ in blast furnace burdens ${ }^{4}$ though individual furnaces are likely to operate, for various reasons, with a predominance of one or another of the three in the make up of their charge. Because sinter and pellets are used in such large proportions, which are still increasing due to the lack of supply of high quality lump ores, there is and will always be a need to improve the properties of sinter and pellets.

The structure of sinter and pellets may be divided into two parts, viz. (1) the mineral and (2) the pores. It is generally accepted that the properties of sinter and pellets are closely related to the mineral constituents $^{5-7,30)}$ and extensive and successful work has been done to improve the properties by achieving proper mineral constituents content under proper process conditions.

It is also generally accepted that pores could play an important role in controlling the property. ${ }^{8,9)}$ Pores provide diffusion path for reactant gases and surface area (pore wall surface) for reaction. Without pores, reaction can only occur through the exterior surface and follow an unreacted-core model ${ }^{10}$ ) and the overall reduction rate is usually low. It is well known that pores also have a large influence on the strength.

Efforts have been made to understand pore formation process in sinter and pellets. It was shown that the porosity of pellets was increased significantly with addition of sawdust, peat, and lignite ${ }^{11,12)}$ due to the increased " voids created by either (1) gaseous evolution (bloating), or (2) decomposition of particles by combustion or reduction within the pellets". The porosity of iron oxide compacts was found to decrease significantly with increasing firing temperature and time in a certain range. ${ }^{13-16)}$ It was reported that the porosity, combined water content and particle sizes of iron ores had an influence on the prosity of sinter. ${ }^{17,18)}$ The influence of chemical compositions of raw mix on the porosity of sinter and pellets have been investigated $^{17,19,20)}$ and the results appeared to show that porosity decreased with increasing either the basicity or the amount of $\mathrm{SiO}_{2}$ due to, according to the authors, the increased amount of melt, and that porosity was increased with increasing the amount of $\mathrm{MgO}$ due to decreased amount of melt. A number of researchers ${ }^{17,19,21)}$ found that porosity of sinter was decreased with increasing coke ratio and they explained that this was due to the increased amount of melt which caused shrinkage.

These results showed that quite a number of factors could have an influence on pore formation in sinter and pellets, and although this is useful knowledge, there still seems to be a lack of satisfactory and comprehensive understanding of the pore formation process itself. The most important and fundamental question of how the pores are actually formed is not yet clear, and probably because of this it has not been possible to establish the concept of the optimum pore structure in sinter and pellets and the ways to achieve it. Therefore the "pores", unlike the mineral part, have not been used as an effective means as they should be to improve the quality of sinter and pellets. A fundamental study of the pore formation mechanism in sinter and pellets ${ }^{22}$ has been conducted at the University of Wollongong, aimed at, first of all, answering the question of how the pores are actually formed, then investigating the effects of various factors on pore formation and finally considering improvement of the quality of the product by establishing optimum pore structure. This paper presents some of the results of that work. 


\section{Experimental}

\subsection{Raw Materials}

The raw materials used were hematite iron ore (Mt. Newman), limestone and coke. The compositions of iron ore and limestone particles are given in Table 1. The limestone was very pure with the $\mathrm{CaCO}_{3}$ content being about $97 \%$ and there was negligible difference in composition between different particle size fractions. The fixed carbon content of the coke was $89 \%$.

\subsection{Preparation of Raw Samples}

The dry raw materials, of desired proportions and particle sizes, were mixed manually in a plastic cup with some water. The amount of water added varied slightly with particle size, being lower when particle size was coarser to avoid slurry condition, but was in the range of $6-8 \%$ of the total weight of dry materials.

The mixture was then compacted into tablets with a die set (inner diameter $=14.40 \mathrm{~mm}$ ) on a normal metallurgical specimen press. The sample in the die was pressed from both sides by top and bottom punches. Samples prepared by this die had a more uniform density distribution along their height than that prepared by a single-end press die which was used in the early stage of the present work. ${ }^{23}$ )

The porosities, or the sizes for a given weight, of raw samples (tablets) could be easily changed by changing the compaction pressure. The porosities were determined by the following equation:

$$
\varepsilon^{\circ}=1-\rho_{b} / \rho_{t}
$$

where $\rho_{b}$ is the bulk density of the sample, i.e., the ratio of the sample weight and volume, $\mathrm{g} / \mathrm{cm}^{3}$, the sample volume was calculated from the sizes measured with a micrometer, $\rho_{t}=1 /\left(X_{f} / \rho_{f}+X_{c} / \rho_{c}+X_{c k} / \rho_{c k}\right)$ is the true density of the sample, $\mathrm{g} / \mathrm{cm}^{3}, \rho_{f}, \rho_{c}$ and $\rho_{c k}$ are the true densities of the iron ore, limestone and coke particles, respectively, measured by grinding the particles to $-45 \mu \mathrm{m}$ and using a density bottle and kerosene (ASTM c-188-44), $X_{f}, X_{c}$ and $X_{c k}$ are the proportions of iron ore, limestone and coke, respectively.

The samples were then dried in a laboratory air oven before sintering. In the following, $D_{f}, D_{c}$ and $D_{c k}$ will refer to the particle sizes of iron ore, limestone and coke, respectively.

\subsection{Sintering}

All the samples, except those identified otherwise, were sintered in an electrical tube furnace. The inner diameter of the tube was $45 \mathrm{~mm}$. The samples were supported by loops of thin KANTHAL wire of $0.2 \mathrm{~mm}$ (each tablet by one loop) and hung on a frame made from KANTHAL wire of $1.15 \mathrm{~mm}$ and were pushed directly to the uniform temperature zone.

The furnace temperature $(\mathcal{I})$ was measured with an accuracy of $\pm 1{ }^{\circ} \mathrm{G}$ by a $\mathrm{Pt}-13 \% \mathrm{Rh}-\mathrm{Pt}$ thermocouple located inside the tube at the centre of the uniform temperature zone, where the sample was held during sintering. When the samples were inserted into the furnace, the furnace temperature which was pre-heated to the desired value dropped due to heat conduction to the sample and the frame, and then started rising in a very short period of time (about $10 \mathrm{~s}$ ) to reach the desired temperature in about 2.5 min which was thereafter maintained steady.

To see how soon the sample could be heated up to the furnace temperature, the temperature at the centre of the sample was measured during preliminary tests with a thin shielded Chromel-Alumel thermocouple (the exterior diameter of the shield was 1.5 $\mathrm{mm}$ ). The sample was made from $85.5 \%$ iron ore $(125-250 \mu \mathrm{m})$ and $14.5 \%$ limestone $(355-425 \mu \mathrm{m})$. The diameter, height and weight of the sample were $14.40 \mathrm{~mm}, 7.21 \mathrm{~mm}$ and $3.25 \mathrm{~g}$, respectively, i.e., similar to most of the samples used in the present work. The result showed that the temperature at the centre of the sample reached close to the set furnace temperature $\left(1265^{\circ} \mathrm{C}\right)$ in about $3.5 \mathrm{~min}$. It could be expected that the surface temperature of the sample would have reached the set furnace temperature earlier. After this period of time, sintering might be regarded as having been carried out isothermally.

As it was found that reaction between limestone and iron ore particles and pore formation process had already occurred during the heating period, the sintering time $(t)$ which will be referred to in the following means the time from the moment the sample was pushed to the uniform temperature zone to the moment it was taken out, i.e., it actually included the heating period.

\subsection{Pore Structure Examination}

The pore structures of the samples were mainly examined microscopically on polished sections for the work discussed in this paper, and the emphasis will be on how the pores are formed and not so much on

Table 1. Compositions of raw materials.

\begin{tabular}{cccccccccccc}
\hline & \multicolumn{2}{c}{ Particle size } & & & & & & & \\
& \multirow{2}{*}{$\begin{array}{c}\text { Range } \\
(\mu \mathrm{m})\end{array}$} & $\begin{array}{c}\text { Average } \\
(\mu \mathrm{m})\end{array}$ & $\mathrm{T} . \mathrm{Fe}$ & $\mathrm{SiO}_{2}$ & $\mathrm{Al}_{2} \mathrm{O}_{3}$ & $\mathrm{CaO}$ & $\mathrm{MnO}$ & $\mathrm{MgO}$ & $\mathrm{P}_{2} \mathrm{O}_{5}$ & $\mathrm{~K}_{2} \mathrm{O}$ & $\mathrm{TiO}_{2}$ \\
\hline \multirow{3}{*}{ Iron ore } & $125-250$ & 188 & 61.3 & 6.0 & 3.1 & 0.32 & 0.04 & 0.05 & 0.08 & 0.033 & 0.13 \\
& $125-350$ & 238 & 61.7 & 5.8 & 3.0 & 0.38 & 0.04 & 0.06 & 0.08 & 0.031 & 0.11 \\
& $710-1000$ & 855 & 62.5 & 5.1 & 2.5 & 0.22 & 0.05 & 0.05 & 0.07 & 0.030 & 0.10 \\
& -1000 & & 61.6 & 6.1 & 3.1 & 0.31 & 0.04 & 0.05 & 0.08 & 0.032 & 0.11 \\
\hline Limestone & & & .75 & 1.3 & .45 & 54.4 & .05 & .60 & .040 & .12 & .05 \\
\hline
\end{tabular}


the final porosity.

\section{Results and Discussion}

\subsection{Pore Formation Phenomenon at Sites of Limestone Particles}

The work started with an investigation on the effect of initial porosity (packing density) of raw samples on the pore structure after sintering as it was commonly believed that the pores might arise mainly from the interparticle voids like in the case of solid state sintered ceramics. ${ }^{24,25)}$ Samples of different porosities were prepared from $85.5 \%$ iron ore $(-1 \mathrm{~mm})$ and $14.5 \%$ limestone $(-1 \mathrm{~mm})$ (sample weight $=2.0 \mathrm{~g}$ ), and sintered at $1280^{\circ} \mathrm{C}$ for $4 \mathrm{~min}$ in a normal muffle furnace. As expected it was found that the higher the initial porosity of the raw sample, the higher the final porosity and the larger the average pore size, and that the pores tended to be more open when porosity was higher. These results were in accordance with common knowledge.

However, it was also found that in the sintered samples there were always some pores which were much larger than the interparticle voids in the raw samples. The very same phenomenon will be seen later in the samples made from mono-size iron ore and limestone particles. The question requiring an answer was the origin of these large pores, as pores from the interparticle voids could not be expected to be that much larger than the voids when the sample did not swell much. This question proved to be the key question which led to the successful finding of the pore formation mechanism in sinter and pellets in the present work.

Following an extensive investigation of various factors considered to be related to the pore formation, it was finally found that the sizes of such large pores were closely related to the sizes of limestone particles. To clarify this phenomenon further, mono-size (narrow range) limestone particles were used, and it was found that the larger the limestone particle size, the larger were the pores formed, as will be seen later, suggesting that pores were formed at the sites of limestone particles. Then when a specially prepared sample consisting of one limestone cylinder (diameter = $2.1 \mathrm{~mm}$, length $=4 \mathrm{~mm}$ ) surrounded by iron ore particles $(125-355 \mu \mathrm{m}, 2.5 \mathrm{~g})$ was sintered at $1280^{\circ} \mathrm{C}$ for $4 \mathrm{~min}$ in the muffle furnace, the limestone cylinder disappeared and at its site a cylindrical pore was formed, as shown in Fig. 1, and when a similar sample consisting of three such limestone cylinders was sintered at $1280^{\circ} \mathrm{C}$ for $4 \mathrm{~min}$, three cylindrical pores were formed at the sites of the three limestone cylinders, respectively. It was observed that sometimes the shapes of the pores formed at the sites of limestone cylinders were quite different from the limestone cylinders when the reaction between limestone and iron ore particles proceeded preferentially in some particular directions.

To prove such a pore formation phenomenon more directly, a hot stage microscope was employed to observe events in situ. The sample (tablet) was made

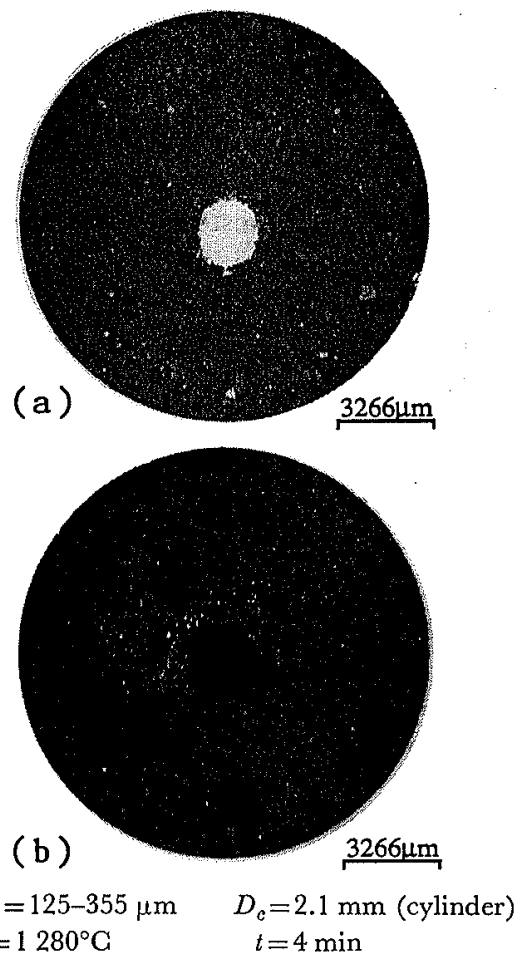

Fig. 1. A limestone cylinder (white) surrounded by iron ore particles in the sample before sintering (a) and the cylindrical pore formed at the site of the limestone cyclinder in the same sample after sintering (b).

from $85 \%$ iron ore $(125-250 \mu \mathrm{m})$ and $15 \%$ limestone particles $(0.71-1.0 \mathrm{~mm})$, compacted with a small die, having both its diameter and height being $5 \mathrm{~mm}$ and a weight of $0.3 \mathrm{~g}$, and heated at different temperatures (1 $\left.240-1300^{\circ} \mathrm{C}\right)$. It was clearly observed that pores were indeed formed at the sites of limestone particles during sintering. Initially, a gap was formed between a limestone particle and iron ore particles around it, and the size of the limestone particle shrank and a pore was being formed synchronously at its place. When a limestone particle had completely " disappeared" (reacted away), a complete pore was thus formed. Liquid flowing over iron ore particles was also observed while the pores were being formed at the sites of limestone particles.

It appeared surprising that such a fundamental phenomenon in iron ore sintering and pelletising processes had not been found hitherto, and it was wondered if similar phenomena had been found in other systems. Further literature survey on the sintering of other sytems (ceramics and powdered metals fields) showed that pore formations in solid state sintering and in liquid phase sintering are quite different, and both are affected by many factors.

In solid state sintering, pores are all from the interparticle voids, ${ }^{24,25)}$ as pointed out earlier. It was probably this concept which had stifled the clear understanding of the pore formation in iron ore pellets and sinter. In liquid phase sintering, some pores, but not all pores, are still from the interparticle voids. In some systems ${ }^{26,27)}$ of liquid phase sintering pores could be formed at the sites of additive particles, which were either melted when melting point was 
reached or reacted with the base particles to form low melting point compounds, which then melted at elevated temperature and flowed away. In some other systems, ${ }^{27)}$ pores were not formed at the sites of added particles after they became liquid. Instead, the liquid formed drew the surrounding particles together. It might be interesting to note that such an understanding of pore formation in some of the systems commonly used in powder metallurgy, was not obtained until many years after these systems had been used. This is probably due to that the pore formation, or more generally, the whole process of liquid phase sintering is affected by many factors in a complex way.

So it appeared that different systems need to be investigated specifically. Nevertheless, such research work and results obtained should have paved the way in understanding the pore formation in iron ore sinter and pellets and helped in finding the results reported here.

Iron ore sintering and pelletizing is generally a liquid phase sintering process. Only pelletizing of very pure iron ore without any additives may be regarded as solid state sintering. As iron ore sintering and pelletizing has many differences from, and seems to be much more complicated than sintering involved in the fields of ceramics and powder metallurgy, then much work is needed to investigate the pore formation process in iron ore sinter and pellets.

\subsection{Effect of Decomposition of $\mathrm{CaCO}_{3}$}

One might think that the decomposition of $\mathrm{CaCO}_{3}$ could have a significant influence on the pore formation in iron ore sinter and pellets. So it appeared important to clarify whether the pores formed at the sites of limestone particles had anything to do with the decomposition of $\mathrm{CaCO}_{3}$.

A test was carried out in the present work using burned lime (samples were made from $85.5 \%$ iron ore and $14.5 \%$ burned lime), and the results were very much the same as when limestone was used (see Sec. 3.4), i.e., pores were again formed at sites of burned lime particles and the larger the burned lime particle size, the larger the pores formed at their sites. This, plus the direct observation on the hot stage microscope (Sec. 3.1) and the results of further detailed microscopic examinations of such a pore formation process (Sec. 3.3) strongly indicated that the pores formed at the sites of limestone particles were not caused by the evolution of $\mathrm{CO}_{2}$ from $\mathrm{CaCO}_{3}$. As to the question whether any $\mathrm{CO}_{2}$ from $\mathrm{CaCO}_{3}$ could be trapped in a melt, some particular experiments may be necessary in order to prove it with certainty. A possibility may, however, be proposed here. It may be very likely that calcination of the limestone would have finished, i.e., all the $\mathrm{CO}_{2}$ would have gone, before any significant amount of liquid could be formed as calcination of the limestone must occur first to produce $\mathrm{CaO}$ which then could react with $\mathrm{Fe}_{2} \mathrm{O}_{3}$ to form compounds and liquid phase. In fact, calcination of limestone starts at about $522^{\circ} \mathrm{C}$ in air and boils at about $903^{\circ} \mathrm{C}^{32}$ ) while the lowest melting point in the system $\mathrm{CaO}-\mathrm{Fe}_{2} \mathrm{O}_{3}$ is $1205^{\circ} \mathrm{C}^{28,31)}$ So it is unlikely that the $\mathrm{CO}_{2}$ from $\mathrm{CaCO}_{3}$ could be trapped in a melt. The possible effect of the decomposition of $\mathrm{CaCO}_{3}$ is probably that it might cause cracking in the pellets during heating if a large amount of limestone is used and the decomposition rate is very high (e.g., when heating rate is very high).

\subsection{Pore Formation Process}

In order to understand in more detail the process of pore formation noted above, samples consisting of $95 \%$ iron ore $(125-250 \mu \mathrm{m})$ and $5 \%$ limestone $(425-$ $500 \mu \mathrm{m}$ ), with a sample weight of $3.25 \mathrm{~g}$ and a porosity of $40.54 \%$, were heated at $1265^{\circ} \mathrm{C}$ for different times from 0 to $15 \mathrm{~min}$ and then examined on a microscope after being polished.

It was found, as expected, that the longer the sample was heated, the higher, on average, was the extent of the limestone and iron ore particle reaction, but not all the limestone particles reacted at the same rate, e.g., some of the limestone particles in the samples completely reacted in less than half the time for others. Hence, the pore formation process will be described in terms of the reaction degree of limestone particles with surrounding iron ore particles, instead of in terms of heating time.

Fig. 2(a) shows a limestone particle surrounded by iron ore particles in a raw sample. There appeared to be more cracks in some limestone particles after being heated for a period of time, probably due to calcination. The limestone after being heated for a period of time (it might be $\mathrm{CaO}$ at this stage) appeared darker on microscopic examination. Fig. 2(b) shows initial calcium ferrite (CF) phase formed between a limestone $(\mathrm{CaO})$ particle and the surrounding iron ore particles. A small quantity of $\mathrm{CF}$ in the voids between the iron ore particles can also be seen.

Fig. 2(c) shows that part of a limestone particle has disappeared and that there is more liquid phase (CF) on the surface and in cracks of the $\mathrm{CaO}$, in between the $\mathrm{CaO}$ and iron ore particles and in the voids between iron ore particles.

Fig. 2(d) shows a small residual quantity of lime $(\mathrm{CaO})$ in a pore formed at the site of the limestone particle. Fig. 2(e) shows a complete pore formed at the site of a limestone particle after it was completely consumed, with liquid phase joining the iron ore particles together.

Another set of experiments was conducted at 1280 ${ }^{\circ} \mathrm{C}$ using samples made from $85.5 \%$ iron ore $(0.71-$ $1.0 \mathrm{~mm}$ ) and $14.5 \%$ limestone $(2.0-2.5 \mathrm{~mm})$, and the results were very much the same as the above, confirming such a pore formation process.

On the above evidence, the pore formation process may be summarized as follows.

(1) During heating, a limestone $\left(\mathrm{CaCO}_{3}\right)$ particle was calcined to $\mathrm{CaO}$, i.e., $\mathrm{CO}_{2}$ was released, accompanied by possible cracking.

(2) $\mathrm{CaO}$ and $\mathrm{Fe}_{2} \mathrm{O}_{3}$ then reacted at the contact surface to form CF.

(3) The CF was melted at higher temperature. Due to surface tension and/or capillary force, the liquid flowed (dispersed) away immediately to: 


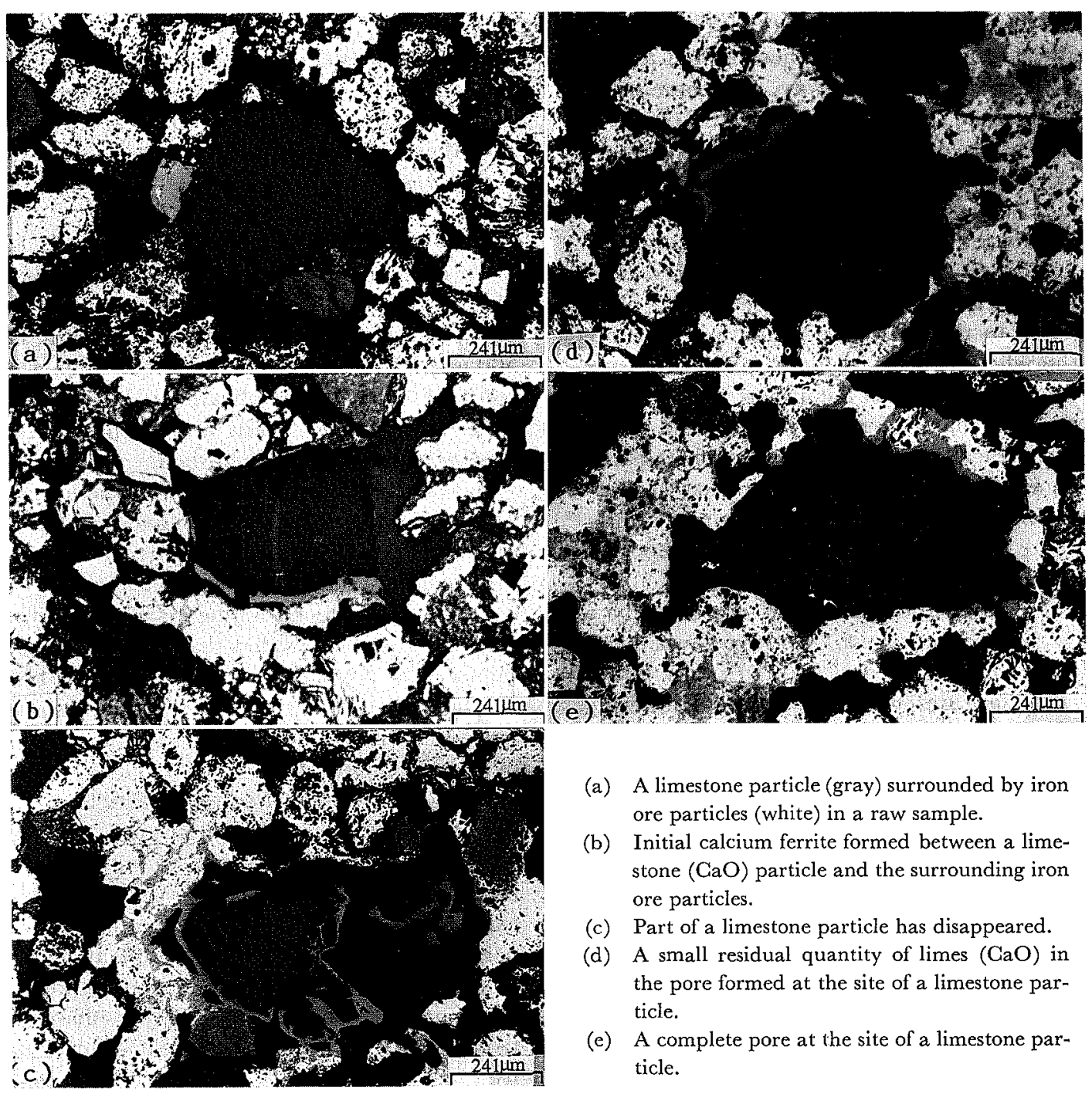

Fig. 2. Pore formation process in iron ore/limestone tablets.

1) surfaces of the $\mathrm{CaO}$,

2) surfaces of surrounding iron ore particles,

3) voids between iron ore particles,

4) inside $\mathrm{CaO}$ through cracks, and

5) inside iron ore particles through open pores.

(4) Reaction between iron ore and $\mathrm{CaO}$ continued at contact points, either directly or through liquid phase as a go-between, and the liquid continued to dissolve the $\mathrm{CaO}$.

(5) More and more liquid was formed and the $\mathrm{CaO}$ became smaller and smaller. The $\mathrm{CaO}$ could also be divided into parts through cracks as observed in some cases.

(6) After the $\mathrm{CaO}$ was completely consumed, a pore was thus formed at its site. When the liquid flowed away from its source, it completely or partially filled some of the voids between iron ore particles, as well as some inner pores in them.

\subsection{Classification of Pores}

The fundamental pore formation mechanism having been established, it is now possible to classify the pores in iron ore agglomerates. Based on the results presented above and the results in Sec. 3.7, pores in iron ore/limestone/coke tablets may be classified according to their origins.

Type 1. Pores formed at sites of limestone particles.

Type 2. While pores are being formed at sites of limestone particles, the liquid phase completely or partially fills some of the voids between iron ore particles. Some voids may also disappear when adjacent iron particles are assimilated together. So Type 2 pores are those unfilled or partially filled voids between iron ore particles.

Type 3. Unfilled or partially filled inner pores of iron one particles. Such inner pores may coalesce during sintering. ${ }^{22)}$

Type 4. Pores formed at sites of coke particles as shown in Sec. 3.7.

Although there might be some other types of pores at different conditions, it is considered that the above types of pores are the main ones. In acid pellets the pores would be mainly from the interparticle voids.

\subsection{Effect of Limestone Particle Size on Pore Formation}

It is always desirable to establish a relationship between all the relevant factors and the pore structure 
in sinter and pellets. This could be done more rationally and comprehensively with the help of the understanding of pore formation mechanism. The effect of limestone particle size and the amount of limestone on the pore structure will be discussed qualitativelly in this section and the next section. The effect of limestone particle size has been briefly reported earlier ${ }^{23)}$ and will be discussed in more detail here.

The samples were prepared from $85.5 \%$ iron ore $(125-250 \mu \mathrm{m})$ and $14.5 \%$ limestone (different sizes), with a sample weight of $3.25 \mathrm{~g}$, and sintered at 1280 ${ }^{\circ} \mathrm{C}$ for $7 \mathrm{~min}$. For comparison of the sizes of the pores formed at limestone particles of different sizes, the samples after sintering shown here were chosen to have sample sizes (volumes) close to each other (in the range of 1.207 to $1.264 \mathrm{~cm}^{3}$ ) from many samples of various sizes made during the course of this study. Also as some dimensional changes occurred during sintering, the raw samples shown here were actually remade so that they had the same sizes (volumes) as those of the sintered samples for comparison of the sizes of the pores in the sintered samples and the sizes of the particles and voids in the raw samples. The initial porosities of these raw samples were in the range of 38.16 to $40.95 \%$.

Figs. 3 to 5 show that the smaller the limestone particles, the smaller the pores (Type 1) formed at their sites, but the greater the number of such pores because the number of limestone particles increased. The Type 1 pores in these three figures were obviously larger than the sizes of the voids between iron ore particles in the raw samples simply because the limestone particles were larger than these voids. It can also be seen that in each of the three figures the Type 1 pores, in general, were larger than the limestone particles, and there were two reasons for this.

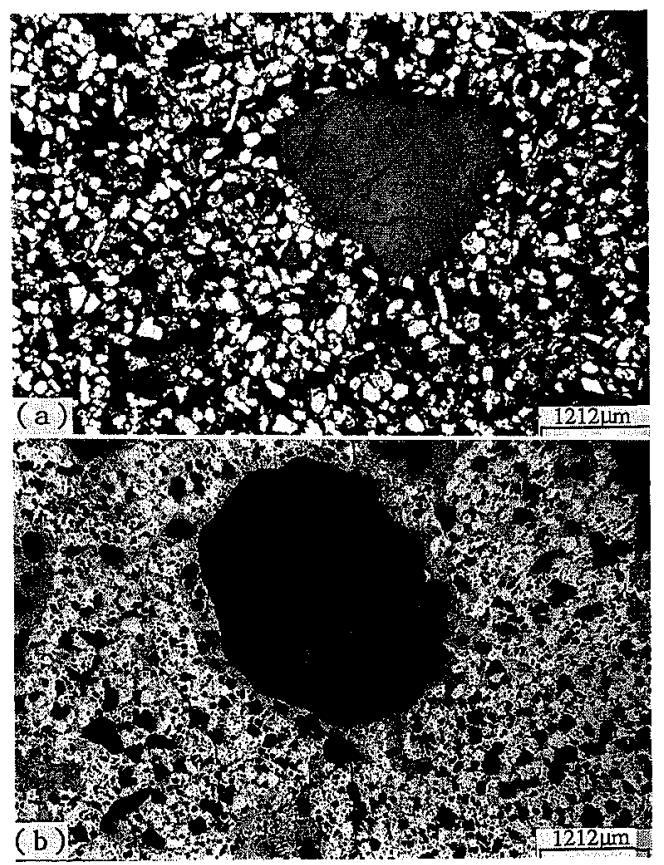

Fig. 3. The structures of the samples $\left(D_{c}=1.4-1.68 \mathrm{~mm}\right)$ before (a) and after (b) sintering.
One was the dissolution of the iron ore particles around the limestone particles, and the other was that some limestone particles were located together and acted as a much larger particle, or close enough to each other to act as a much larger particle when the iron ore particles in between them could completely become liquid and flow away. It is also clear that with decreasing limestone particle size, the overall pore structure was more uniform in terms of pore size and dispersion of porosity in the sample. It can also be seen that while pores were formed at the sites of limestone particles, liquid phase filled partially or

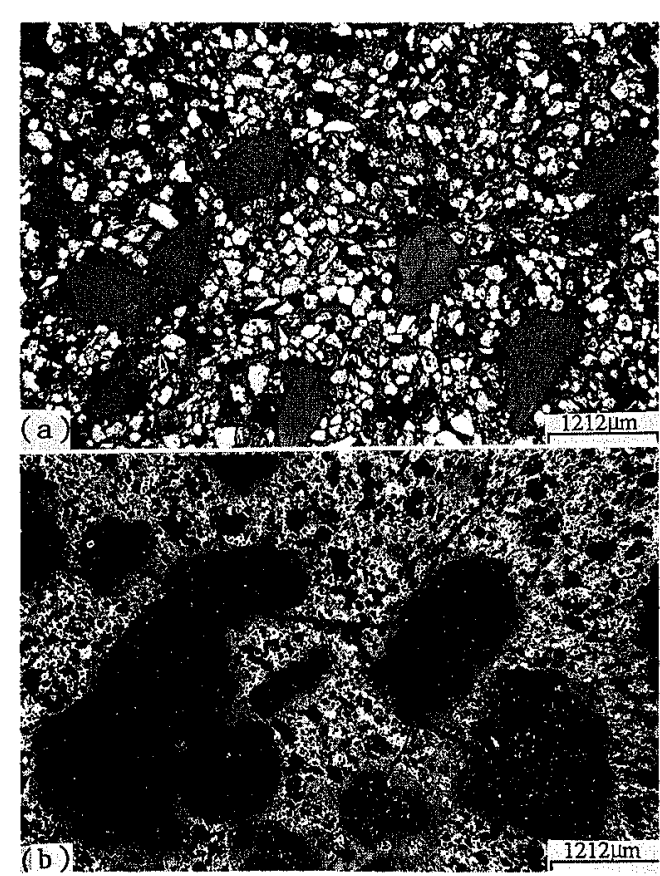

Fig. 4. The structures of the samples $\left(D_{c}=0.71-1.0 \mathrm{~mm}\right)$ before (a) and after (b) sintering.

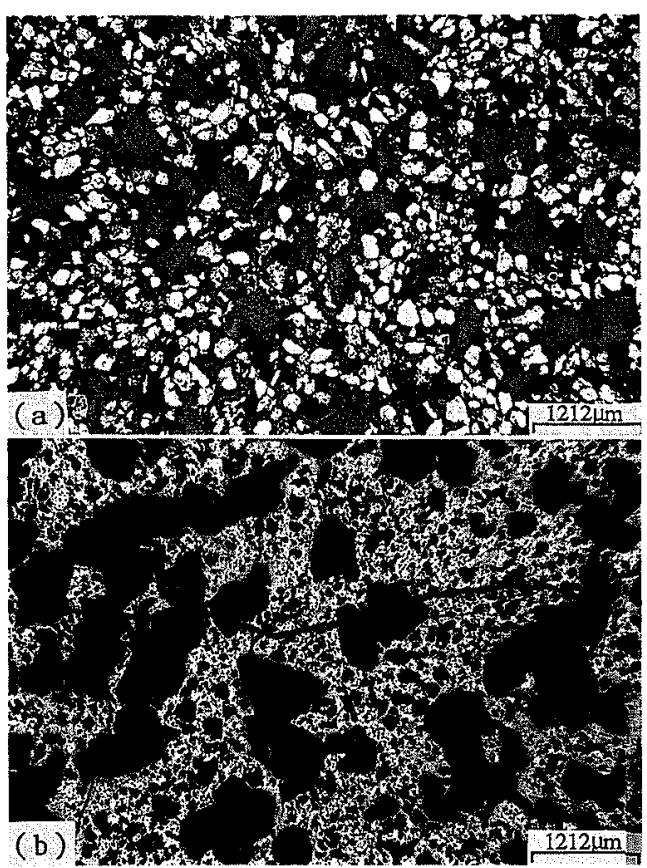

Fig. 5. The structures of the samples $\left(D_{c}=355-500 \mu \mathrm{m}\right)$ before (a) and after (b) sintering. 
completely the voids around. The filling of these voids by liquid tends to make them closed or isolated, causing a loss of surface area available for reaction.

It is important to note the simple fact that at same porosity, a decrease of pore size and increase of pore number means an increase in surface area which is extremely important for high reducibility. Also with decreasing limestone particle size, the chance of the pores formed at their sites being open is higher due to the increased number of such pores. ${ }^{22)}$ This probably means that the open porosity would be higher with decreasing limestone particle size.

Such an effect of limestone particle size on pore structure was further proved when a number of parameters were changed in wide ranges, such as iron ore particle size, porosity, temperature, amount of limestone, etc.

An interesting and important result mas the formation of open pore structure. When limestone particle size was $53-75 \mu \mathrm{m}$ or smaller, they were dispersed quite uniformly and there was one or more limestone particle in almost every void between iron ore particles, and after sintering every such void became a pore (termed as Type 1-2) and a very uniform pore structure was formed (Fig. 6). More importantly, at such lime stone particle sizes, all these pores (Type 1-2) were connected to each other and were open. Such an open pore structure is obviously desirable for high reducibility.

\subsection{The Effect of Amount of Limestone on Pore Formation}

The constituents and sintering conditions of the samples used for this purpose are shown in Table 2. The raw samples were compacted under same pres-

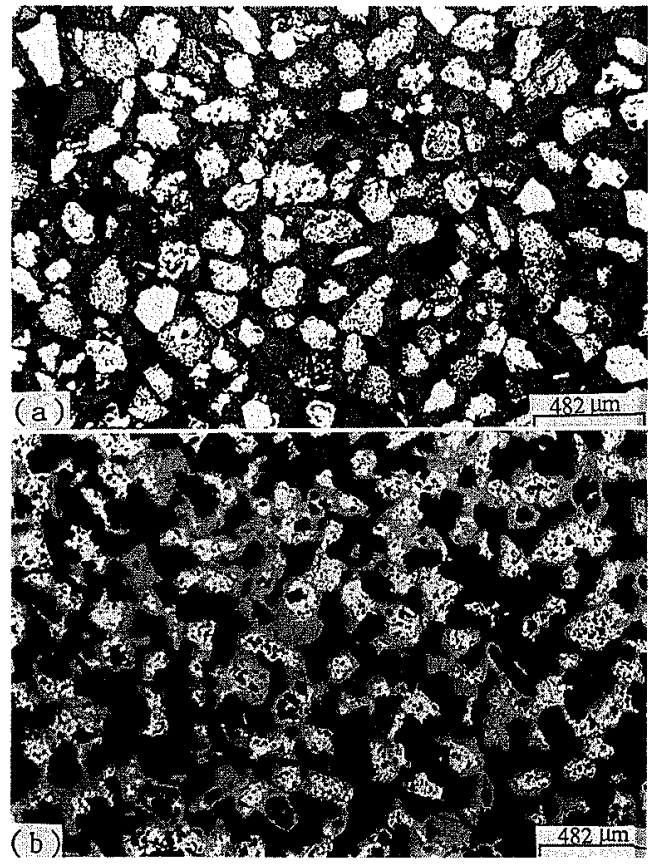

Fig. 6. The structures of the samples $\left(D_{c}=53-75 \mu \mathrm{m}\right)$ before (a) and after (b) sintering

Note: A higher magnification than that in Figs. 3 to 5 was used to show the fine limestone particles in this figure. sure. The porosity of the raw sample was lower with increasing the amount of limestone due to the difference in particle size between the iron ore and limestone (The sample size was actually larger with increasing the amount of limestone due to the lower density of the limestone than that of the iron ore). The amount of limestone had an effect on the dimensional change during sintering. As can be seen in Table 2, with $3 \%$ limestone, the sample appeared to have shrunk very slightly, and with $5 \%$ limestone, the sample swelled very slightly. The swelling of the sample increased with amount of limestone from 5 to $20 \%$. With $25 \%$ limestone, the sample shrank obviously. The dimensional change during sintering is a complicated process and needs to be discussed specifically elsewhere.

It was obvious that with increasing the amount of limestone from 3 to $14.5 \%$ the number of Type 1 pores (formed at limestone sites) was increased simply because the number of limestone particles increased. And accordingly the number of Type 2 pores (unfilled or partially filled voids) should decrease because the number of voids between iron ore particles in which there was not any limestone particle was decreased and the amount of liquid was increased. Figs. 7(a) to 7 (c) show these results.

As shown in Figs. 7(a) and 7(b), it is obvious that with 3 and $5 \%$ limestone, only some of the interparticle voids around the limestone particles were completely or partially filled, and most of them were unfilled and remained open. With $14.5 \%$ limestone, as shown in Fig. 7(c), almost all the interparticle voids were completely or partially filled, and the average size of Type 1 pores appeared to be larger.

With $20 \%$ limestone, as shown in Fig. 7(d), the number and average size of Type 1 pores further increased. In this case, more liquid was formed and the filling of the interparticle voids and dissolution of iron ore particles by the liquid became notable. As a result Type 2 pores became more spherical and their number was decreased.

The much larger sizes of Type 1 pores in Samples $\mathrm{C}$ and particularly D (Figs. 7(c) and 7(d)) than those in Samples A and B (Figs. 7(a) and 7(b)) were due to that some limestone particles were located together or very close to each other.

With $25 \%$ limestone, as shown in Fig. 7(e), much more liquid was formed and the iron ore particles

Table 2. Properties and sintering conditions of Samples A to $\mathbf{E}$.

\begin{tabular}{cccccr}
\hline & $\begin{array}{c}D_{f} \\
(\mu \mathrm{m})\end{array}$ & $\begin{array}{c}D_{c} \\
(\mu \mathrm{m})\end{array}$ & $\begin{array}{c}X_{c} \\
(\%)\end{array}$ & $\begin{array}{c}\varepsilon^{\circ} \\
(\%)\end{array}$ & \multicolumn{1}{c}{$\begin{array}{c}\text { LDG } \\
(\%)\end{array}$} \\
\hline A & $125-250$ & $425-500$ & 3 & 42.06 & -0.51 \\
B & $125-250$ & $425-500$ & 5 & 41.68 & 0.61 \\
C & $125-250$ & $425-500$ & 14.5 & 40.04 & 3.18 \\
D & $125-250$ & $425-500$ & 20 & 39.95 & 6.56 \\
E & $125-250$ & $425-500$ & 25 & 38.19 & -11.82 \\
\hline
\end{tabular}

Raw sample weight $=3.25 \mathrm{~g} \quad T=1280^{\circ} \mathrm{C} \quad t=10 \mathrm{~min}$

LDC: Linear dimensional change during sintering. Negative sign means shrinakge. Positive sign means swelling. 


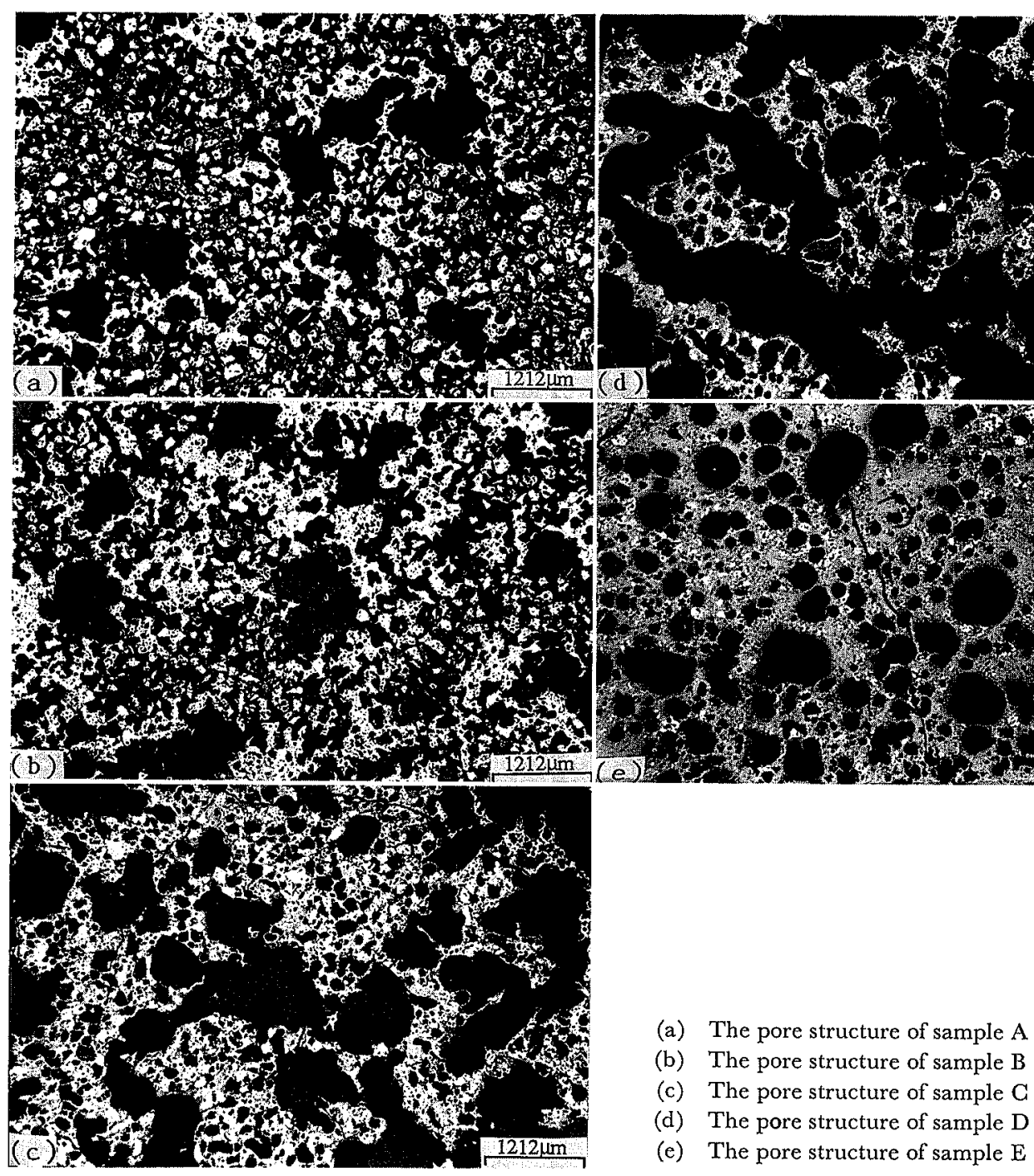

Fig. 7. Effects of amount of limestone on pore structures.

were nearly completely dissolved. The pore structure changed dramatically due to the large amount of liquid and severe shrinkage. The sizes and total number of pores were smaller and those large pores that were formed at the sites of limestone particles as in Fig. 7(d) were rarely observed. Almost all the existing pores were very spherical and isolated and, in some areas, there were no pores present at all. This kind of pore structure would be obviously very bad for reducibility.

It is a well known fact that basicity $\left(\mathrm{CaO} / \mathrm{SiO}_{2}\right)$ has a strong influence on the mineral constituents and the properties. As a change in bacisity means a change in the amount of limestone for a given $\mathrm{SiO}_{2}$ content, it would be accompanied by a change in pore structure according to the present results. Such a pore structure change, as well as the change in mineral constituents, should be considered when analyzing the influence of basicity on the properties, and further work on this aspect may be worthwhile.

\subsection{Effect of Coke on Pore Formation}

Coke is always added to sintering mix as the only source of heat in the sintering process. Coke or coal is sometimes added to pelletizing mix too. ${ }^{29)}$ This section discusses the effect of coke on pore formation.

The samples were made from $80.71 \%$ iron ore $(125-250 \mu \mathrm{m}), \quad 13.69 \%$ limestone $(53-75 \mu \mathrm{m})$ and $5.6 \%$ coke $(1.0-1.4 \mathrm{~mm}, 0.5-0.6 \mathrm{~mm}$, and 53-75 $\mu \mathrm{m}$, respectively), with a sample weight of $3.0 \mathrm{~g}$, and were heated at a furnace temperature of $1180^{\circ} \mathrm{C}$ for 15 min. Before sintering these three samples (of different coke particle sizes) had almost same volume (1.18 to $1.19 \mathrm{~cm}^{3}$ ) and same porosity (33.0 to $33.2 \%$ ). Slight linear swelling (2.0 to $3.1 \%$ ) occurred during sintering, but they still had volumes close to each other $\left(1.26\right.$ to $\left.1.29 \mathrm{~cm}^{3}\right)$, so the pore sizes in these three samples were comparable.

Microscopic examination of the samples after heating showed that the limestone particles seemed to have all disappeared (reacted with iron ore particles), suggesting that the temperature of the samples was higher than $1205^{\circ} \mathrm{C}$ which is the lowest eutectic temperature in the $\mathrm{Fe}_{2} \mathrm{O}_{3}-\mathrm{CaO}$ system. This also means the temperature of the samples was higher than the furnace temperature due to the heat generated by the combustion of coke in the samples.

If only iron ore and limestone of the same particle 
sizes and proportions were used without coke, a uniform pore structure should be achieved after sintering, similar to that in Fig. 6 where almost every void between iron ore particles became a pore.

Fig. 8 shows that when coke particles were added, pores were formed at the sites of coke particles when they burned off, as well as at the site of limestone particles. When the coke particle size was 1.0-1.4 $\mathrm{mm}$, coke particles had not completely burned off, but it is obvious that relatively large pores were formed at their sites with some coke residual (Fig. 8(a)). When the coke particle size was $0.5-0.6 \mathrm{~mm}$, coke particles had nearly completely burned off and the sizes of the pores formed at their sites were smaller (Fig. 8(b)) than those when the coke particle size was 1.0-1.4 mm. When the coke particle size was 53-75 $\mu \mathrm{m}$, coke particles, like the limestone particles, were quite uniformly dispersed and there was one or more coke particles in almost every void between iron ore particles, and during heating, all the coke particles burned off and a quite uniform pore structure was formed as shown in Fig. 8(c).

When these samples were heated at higher furnace temperatures, 1250 and $1270^{\circ} \mathrm{C}$, respectively, the

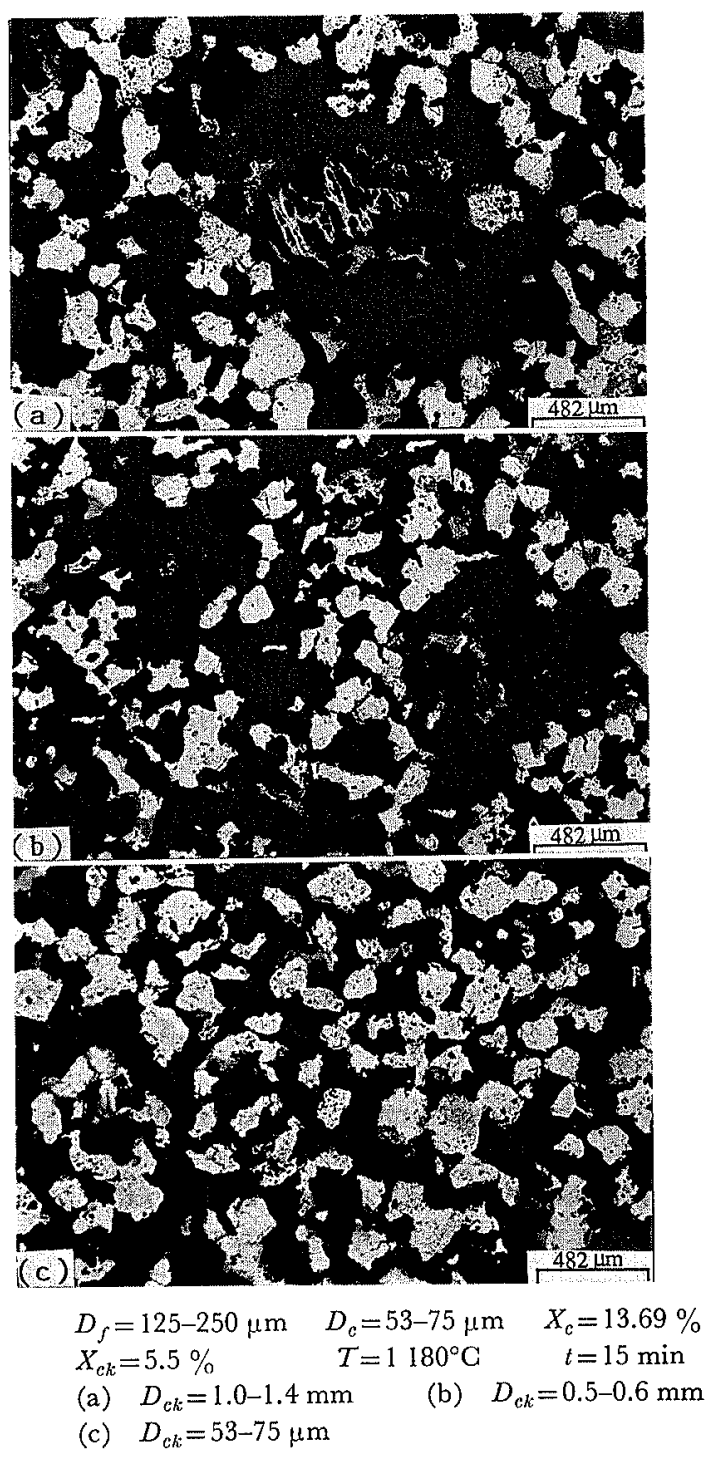

Fig. 8. Effects of coke particle size on pore structures. results still showed that the larger the coke particles the larger the pores formed at their sites. But at such high temperatures, severe shrinkage occurred to the sample made from coke particles of $0.5-0.6 \mathrm{~mm}$ and particularly the sample made from coke particles of 53-75 $\mu \mathrm{m}$, and pores tended to become isolated, as the temperatures in the samples could have been very high. Also, reduced $\mathrm{Fe}_{3} \mathrm{O}_{4}$, and metallic iron were observed in the samples sintered at these high temperatures. As the presence of $\mathrm{FeO}$ (or $\mathrm{Fe}_{3} \mathrm{O}_{4}$ ) has an effect on the formation and amount of liquid phase, it would have an effect on pore structure.

Furthermore, similar results could probably be expected when other combustible carbonaceous materials are used such as peat, lignite, and sawdust. Addition of such materials could not only have an influence on total porosity ${ }^{11,12)}$ as mentioned earlier, but also their particle sizes could have an effect on the pore structure according to the present results.

Finally, we briefly point out that the fundamental pore formation mechanisms found with the tablets shown above have been proved to be at work in real pellets and sinter. Pore formation in pellets was very much the same as in the tablets, but pore formation in sinter was more complicated than in pellets due to the large range of particle sizes and the existance of agglomeration. Also the results appeared to show that the influence of the air flow through the sintering bed was not as significant as one might think and that the large pores in sinter were very unlikely to be caused by the air flow through the sintering bed. These results will be discussed in detail in another paper.

\section{Conclusions}

The results of the present study have shown that:

(1) The fundamental pore formation mechanisms in oron ore pellets and sinter are:

(a) Pores are formed at sites of limestone particles. Limestone particles react with iron ore particles to form low melting point compounds which are melted at elevated temperature, and the liquid phase then flows away immediately due to either surface tension and/or capillary force. When the limestone particles are consumed completely, pores are thus formed behind;

(b) When the liquid phase flows, it fills completely or partially the adjoining interparticle voids and some inner pores of iron ore particles;

(c) Pores are formed at sites of coke particles after they burn away.

(2) Limestone particle size, amount of limestone, and coke particle size have a strong influence on the pore structure and therefore may be used as effective means to change the pore structure.

\section{Acknowledgements}

We are grateful to Messrs R. Nightingale and J. Simpson of BHP Steel International, Port Kembla for their interest, assistance and many valuable discussions in the course of this study. The financial 
support by BHP Steel International is greatly acknowledged.

\section{REFERENCES}

1) R. V. Williams: Control and Analysis in Iron and Steelmaking, Butterworths, London, (1983), 10.

2) K. Meyer: Pelletizing of Iron Ores, Springer-Verlag, Berlin, (1980), Chap. 1.

3) Y. Ishikawa, K. Sugawara and Y. Umezu: Agglomeration 77, Vol. 2, K.V.S. Sastry, ed., AIME, New York, (1977), 503.

4) R. D. Walker: Modern Ironmaking Methods, Inst. Met., London, (1986), Chap. 3.

5) J. Ostwald: BHP Tech. Bull., 25 (1981), No. 1, 13.

6) G. Price and D. Wasse: Developments in Ironmaking Practice-Proceedings of Conf., Iron Steel Inst., London, (1972), 32.

7) A. K. Biswas: Principles of Blast Furnace Ironmaking, Cootha Publishing House, Brisbane, (1981), Chap. 6.

8) A. Unal: Trans. Inst. Min. Metall., Sect. C, 95 (1986), C179.

9) S. P. Trushenski, K. Li and W.O. Philbrook: Metall. Trans., 5 (1974), 1149.

10) O. Levenspiel: Chemical Reaction Engineering, John Wiley \& Sons Inc., New York, (1972), Chap. 12.

11) K. Taguchi, T. Sato and S. Fukihara: Ironmaking Proc., Vol. 39, AIME, Washington, D.C., (1980), 363.

12) S. A. Elmquist, J. Huse and C.A. Czako: Ironmaking Proc., Vol. 41, AIME, Pittsburgh, PA, (1982), 483.

13) J. R. Wynnyckyj and T.Z. Fahidy: Metall. Trans., 5 (1974), 991.

14) J. K. Wright: Powder Technology, 14 (1976), 103.

15) J. K. Wright: Powder Technology, 30 (1981), 185.

16) J. R. Wynnyckyj and R. J. Batterham: Proc. of the 4th Int. Symp. on Agglomeration, Toronto, Canada, ISS-
AIME, (1985), 957.

17) S. Sato, T. Kawaguch, M. Ichidate and M. Yoshinaga: Tetsu-to-Hagané, 73 (1987), 804.

18) H. Kokubu, T. Kodama, H. Itaya and Y. Oguchi: Trans. Iron Steel Inst. Jpn., 26 (1986), 182.

19) P. Lecomte: CRM, Metall. Rep., (1971), No. 28, 25.

20) S. G. Panigraphy, M. Jallouli and M. Rigaud: Ironmaking Proc., Vol. 43, AIME, Chicago, IL, (1984), 233.

21) E. Kasai, R. R. Lovel, W. J. Rankin and Y. Omori: Tetsuto-Hagané, 75 (1989), 228.

22) Y-H. Yang: Ph.D Thesis to The University of Wollongong, (1990).

23) N. Standish and Y-H. Yang: J. Maier. Sci. Lett., 7 (1988), 542.

24) W. D. Kingery, H. K. Bowen and D. R. Uhlmann: Introduction to Geramics, 2nd. Ed., John Wiley \& Sons, New York, (1976).

25) R. Hogg and C. L. Hwang: Agglomeration 77, Vol. 1, K.V.S. Sastry, ed., AIME, New York, (1977), 198.

26) O.J. Kwon and D. N. Yoon: Int. J. Powder Metall. Powder Tech., 17 (1981), 127.

27) R. M. German: Liquid Phase Sintering, Plenem Press, New York, (1985).

28) W-K. Lu, V. Hegde, V. Trofimov and Y. Lu: Ironmaking Proc., Vol. 40, AIME, Toront, Ganada, (1981), 258.

29) K. Meyer: Pelletizing of Iron Ores, Springer-Verlag, Berlin, (1980), 138.

30) Q.D. Zhou and L. T. Kong: Theory and Practice of Iron Ore Agglomeration (in Chinese), MMI Press, Beijing, (1985).

31) E. M. Levin, C. R. Robbins and H. F. McMurdie: Phase Diagrams for Ceramicists, Am. Ceram. Soc., Columbus, $\mathrm{OH}$, (1964).

32) E. T. Turkdogan, R. G. Olsson, H. A. Wriedt and L. S. Darken: Trans. SME-AIME, 254 (1973), 9. 